\title{
Role Of Mass Media In Awareness Raising For Sexually Transmitted Infections (STI's)
}

\author{
Shagufta Nasreen \\ \& \\ Aliyah Ali \\ Women's Studies \\ University of Karachi
}

\begin{abstract}
One of the major threats faced in the fast changing world is of communicable diseases and infections such as Sexually Transmitted Infections (STI's). In Pakistan where reproductive health related issues are not discussed openly, it is difficult to find any countrywide data on the prevalence of STI's. There are, however, a few selected small sample studies confirming its prevalence in general public as well in high risk groups. At policy level we find little recognition and willingness to deal with these infections. However this process can be geared up with the help of mass media for raising awareness. This paper seeks to examine the role of media in creating public awareness and in breaking the silence against these 'taboo' infections and make people aware about its prevention and cure.
\end{abstract}

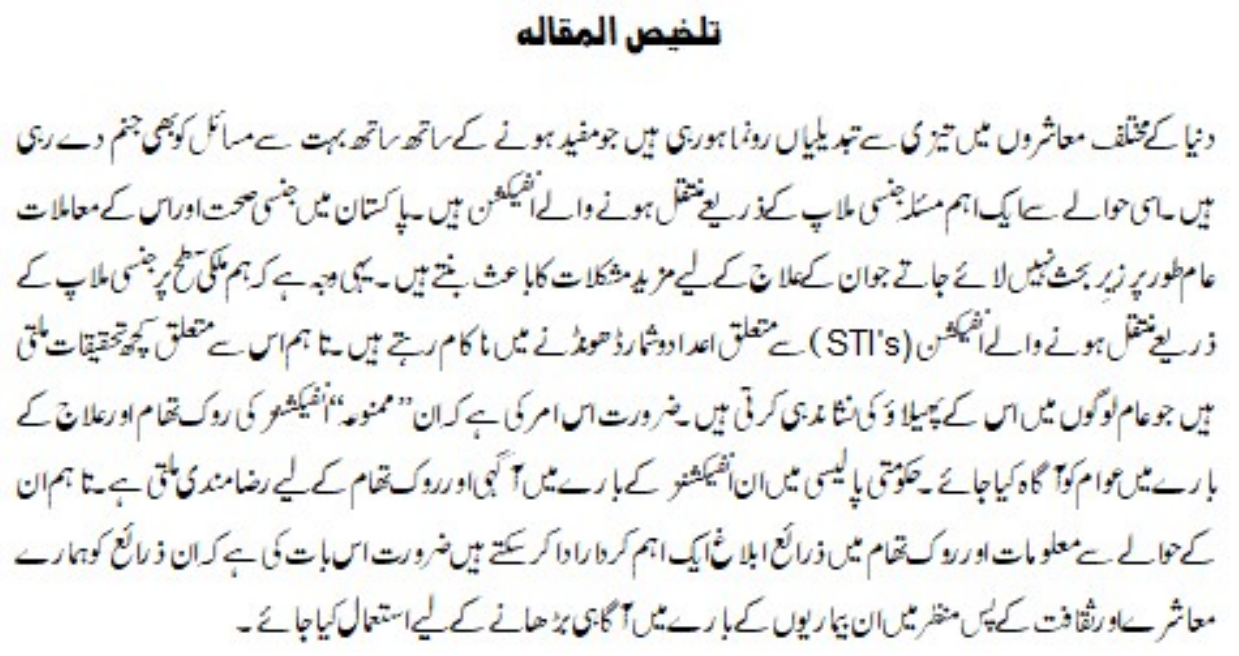

\section{Introduction}

Pakistan is a developing country. Every year economic reports from government show progress in economy, however social indicators do not show a good position. According to Human development Report 2005, its ranking is 135 and $32.1 \%$ people are living below poverty line. Increase in prices of daily routine items is pushing people to work on 
hard conditions including low salaries, long working hours and less job security. Globally the informal sector today is a major provider of urban jobs constituting some 50 to 60 percent of the workforce in many Southeast and South Asian cities. According to an estimate majority of the workforce consists of the female workers (Chen, M.S., \& O'Connel,L.(1999). A World Bank report shows that in the in mid-nineties some two million women were working in the informal sector in Pakistan, whereas some 0.75 million women were working in the informal sector and some 0.75 million females emerged in micro- enterprises at various levels both in manufacturing and trade (Hussein,1994). Majority of population in Pakistan live in rural areas where availability, accessibility and quality of health and educational facilities are low. In urban areas majority of the population live in urban slums which lack facilities of basic life. The growing number of urban slums is due to urban rural migration for the search of better life style however ending up in living unsafe risky environment socially, economically and environmentally. In this scenario the status of women in Pakistan also shows a grim picture. Human Development Report 2005 shows that female literacy rate is $35.2 \%$ as compared to male $61.7 \%$. Estimated earned income of females is Rupees 1050 as compared to Rupees 3082 of men. Informal sector has increased and women are becoming part of it mainly as home based workers, self-employed women, piece rate workers and domestic helpers ILO-(2004). On the other hand female professional and technical workers are 26 percent of the total and female legislatures, service officers and managers are $2 \%$ of the total. Health indicators also show that a lot is needed to be done in this area. Total fertility rate per women is 4.1. Maternal mortality rate is very high. However in some areas there has been improvement in numbers. After the year 2000 Government policies encouraged women to become part of politics. So the number of women in parliament shows marked increase as compared to the past as seats in parliament as percent of total is $20.6 \%$ (HDR, 2005).

Statistics Related to Women of Pakistan

\begin{tabular}{|c|c|c|c|c|c|c|}
\hline Year & Ranking & $\begin{array}{c}\text { Adult illiteracy } \\
\text { rate }\end{array}$ & $\begin{array}{c}\text { Maternal } \\
\text { mortality } \\
\text { ratio }\end{array}$ & $\begin{array}{c}\text { Total } \\
\text { population }\end{array}$ & Fertility rate & $\begin{array}{c}\text { Expenditure on } \\
\text { health }\end{array}$ \\
\hline 2000 & 135 & 56 & n/a & 148.2 & 5 & 0.8 \\
\hline 2001 & 127 & 55 & n/a & 137.6 & 5.5 & 0.9 \\
\hline 2002 & 138 & 56.8 & n/a & 141.3 & 5.5 & 0.7 \\
\hline 2003 & 144 & 56 & n/a & 146.3 & 5.1 & 0.8 \\
\hline 2004 & 142 & 58.5 & 530 & 149.9 & 5.1 & 1 \\
\hline 2005 & 135 & 51.3 & 530 & 151.8 & 4.3 & 1.1 \\
\hline
\end{tabular}

Source: Human Development Reports

This brief statistical introduction shows that regardless of the claims of government of growth in GNP, from year 2000 to 2005 the social indicators do not show much improvement. There are many reasons behind it. For instance Asian Development Bank report on health sector shows an increase in making buildings and capacity improvement 
but service out comes are not satisfactory due to corruption, absentee staff, missing equipment and medical supplies (Kiani, K. 2005).

In this article we will discuss the awareness raising of another important aspect of health which is a greater need of present i.e. awareness of health issues especially related to Sexually Transmitted Infections (STIs) for general public, adolescents and women. In Pakistan majority of the population is unaware of basic health. When they get ill they go to peer and faqirs. ${ }^{1}$ When illness increases they go to a doctor. In Pakistan proportion ratio of qualified doctors to patients is low and varies in urban and rural areas. Private hospitals are increasing but they are very expensive. Health policy is curative and not preventive. Although there is an increase in budget for health sector (see table) but the need is to focus both on quantity and quality. Along with other policy measures public awareness about health in general and about HIV/AIDS and STI's in specific is necessary. In Pakistan apart from government there are different NGOs working on these issues, especially related to HIV/AIDS. In this regard usually seminars and workshops are held for this purpose, IEC ( Information, Education and Communication) materials are developed by both government departments and NGOs but they are limited to the people related to the fields of medicine, representatives of NGO's or representatives of relevant departments. General public do not get benefit from such efforts as usually they are reported in newspapers in brief.

Reproductive health is usually considered a topic which is confined to child birth and pregnancy related topics. STI's are treated as separate subject and people avoid discussions about STI's as it is considered a taboo subject. Studies show that we should research about the prevalence and raise awareness about prevention and cure of STI's and HIV/AIDS. Research shows that societies are changing rapidly all over the world. The "global village" concept and fast growing information technology have brought into our households structural changes beyond our imagination. Religious and traditional values have begun to loose their meaning. Cultural invasion for the purpose of profit is actually leading children and youth to the verge of destruction. Capitalist societies for the sake of profit have been manipulating ethical values globally. Sensational commercials, products stimulating sexuality are present all around creating a culture of anxiety with no guidance to deal with conflicts arising from external input. Global travelling causes the spread of HIV which is dealt carelessly by officials and society. According to a research study sex education for adolescents is necessary, however in order to be effective it needs to be dealt at different level. Hence planning and implementation of culturally appropriate interventions in support of youth and adolescents are essential. ${ }^{2}$

Sexually transmitted diseases or venereal diseases are a term used for infections acquired mainly through sexual contact. STDs are generally graver in women, in whom diagnosis is often more difficult and treatment less available than for men, untreated they can lead to infertility or cause miscarriage, premature birth or infection of the new born. Untreated 
STIs are thought to account for $10-15$ percent of foetal wastage and 30-50 percent of antenatal infections and are linked to cervical cancer and ectopic pregnancy. They contribute to the incidence of blindness, brain damage, pelvic inflammation, spontaneous abortions ectopic pregnancies and cervical cancer and are a major cause of infertility (Glasier, Anna et. al, 2007).

The spread of sexually transmitted Aids increased dramatically during the 1980s and continued through the 1990s. In the late 1990s it was estimated that 10 to 12 million new cases were reported to disease control centres in the United States each year and an estimated 250million sexually transmitted infections occur each year and the number is increasing. ${ }^{3}$ HIV \& STIs constitute the second major cause of disease burden after maternity related causes in young adult women in developing countries (Glasier, A. (et.al) 2007). There are different studies related to STIs in Pakistan. National Survey of Sexually Transmitted diseases 2001 shows that there is lack of data on STD's prevalence in Pakistan and to cater it properly there is a need to do a survey at national level. General Population STI Prevalence in Pakistan Study 2000-2001 confirmed the prevalence in study population but due to limited sample size it is not a representative data of all women. However it suggested further studies and incorporation of STI management and detection in women's health related programs (NACP-2001).

Epidemiological Fact Sheet (EFS) sheets on HIV/AIDS and STI's for Pakistan, 2006, shows no statistics about STI's. It gives demographic details, statistics about HIV/AIDS but most of the statistics related to STIs is not available. According to this report it was shared with National AIDS Control Program for review and comments but is based on official estimates (EFS-Dec.2006). There are other small scale researches showing the prevalence of STI's. The study of N. Rehan was focused only on men showing that $60 \%$ of his respondents were married and majority of them live with their families. More than fifty percent acquired the infection heterosexually. The study confirmed STI prevalence in Pakistan and suggested cultural appropriate health education and developing IEC material for its awareness (N.Rehan). This shows that due to lack of awareness these infections are spreading among people silently.

There are many reasons for STI prevalence and its increase day by day in the country such as, socioeconomic, cultural and religious causes other reasons are, increasing rate of poverty, urbanization, cultural myths and taboos, religious patterns, lack of health facilities, untrained mid wives and insufficient number of lady health visitors in comparison with the increasing population of the country and involvement of the street children in sexual activities. Another major cause of increasing ratio of STI's is unsafe sex during travel and internal migration, a large number of people migrated from rural areas to urban due to unemployment and poverty. Truck drivers, sex workers, inject able drug users; blood donors are included in high risk groups in this case planning and cure of these infections. 
At policy level there are some major steps taken. The National Health policy of Pakistan concentrates in the first key area of policy, on the communicable diseases. According to the clause no1.1.8 the PC-I on HIV-AIDS will be enlarged to incorporate the following components - prevention of HIV transmission through health education; surveillance system; early detection of Sexually Transmitted Infections (STIs); Improved care of the affected Persons; and promotion of safe blood transfusion. A uniform law will be a part of projects and planning emerging out to focus on Blood Control Authorities in the Provinces6. An important issue is proper use of funds for the awareness rising of sexually transmitted infections and prevention (National Health Policy Pakistan-2001).

The major challenge in this regard would be considering STI's a taboo subject. People in general and especially women hesitate to discuss such issues. This creates problems for adolescents as well who one hand are watching satellite channels, using internet and playing video games containing sex related information but do not know how to protect themselves. STI's are considered a disease of people of "bad" character like sex workers, addicts homosexual etc. Usually society's behaviour is negative towards such people. "...they have got what they deserve and may well left to perish...yet it is an attitude which should not be ignored for it still carries weight with many who are too weak to withstand those who juggle with fine moral phrases" (Kerber, K.L., 2005).

Media can be used as a powerful source to change people's behaviour and attitudes towards certain things. Communication is the process through which a message could be conveyed. "We define communication as the process by which an idea is transferred from a source to a receiver with the intent to change his [her] behaviour. The source transfers the idea with intent to modify the behaviour of a receiver (Rogers, E.M. 1973). Media to some extent is already working on these lines. Earlier in Pakistan the only focus was on state television however after 2000 private channels have flourished. A new open media policy caused many new private channels to spring up over the years but PTV (Pakistan Television) still has its stronghold and covers a wide range areas. For instance PTV1 cater to $86 \%$ of the population on the other hand private channels has large viewer ship in urban areas (Ahmed, K. \& Haroon, U 2003). On private channels there are different talk shows in which "taboo" issues are discussed for example "Equinox" on DAWN TV, "Uljhan Suljhan" on GEO TV are some examples. On state television before the news at 9:00 pm, advertisements are aired about prevention from HIV/AIDS. For this kind of communication there is a special kind called" Taboo communication". Taboo communication is little recognized and insufficiently studied. It is important because of its distinctiveness from other kinds of communication behaviour. It is that category of message transfer in which the messages are perceived as extremely private and personal in nature. Rogers, E.M. (1973) Society categorizes certain topics as relatively more taboo than others because such issues threaten important social values. 18 One strategy for facilitating taboo communication is to seek to encourage more widespread communication about the taboo message and thus to reduce the taboo nature of that 
message. There are different strategies adopted in taboo communication. Another strategy is to re-label the taboo topic with different words and symbols (Rogers, E.M. 1973).

In Pakistan STI's detection, prevention and cure has been included in the policy and budget is allocated for it. The need now is to develop awareness material in the context of our society. For this purpose we can divide our groups on the bases of age and gender and develop Information, Education and Communication (IEC) material according to their needs. Awareness messages are needed to be developed during programs which are popular amongst the adolescents and women can be very helpful. Discussions and talk shows with doctors, people of relevant organizations, religious leaders can also help in such case. Life Skills projects initiated in Pakistan for adolescent age in schools and street children is a good example initiated from Non Governmental Organizations. UNICEF, UNFPA, World Population Foundation (WPF) and its partners organizations such as APWA in Karachi, PVDP in Peshawar, HANDS in Matiyari (Sindh), IDSP in Quetta, AWAZ in Multan, Aahung, Azad Foundation, LDM, PAVHNA ${ }^{4}$ and many more working on such projects. They use different methodologies such as using a prepared text book for school children, based on acquiring knowledge and learning communication skills, decision making skills, self awareness, and avoiding risk taking behaviours. This course is supported by videos related to the issues related to adolescents with special reference to body and emotional changes in adolescent age, prevention from HIV/AIDS and abuse topics. The need is to make strategies and develop material for mass media for awareness raising of other age groups and gender.

\section{End Notes:}

$1 \quad$ Traditional healers

2 Riaz, Iffat. (January2000) "Need of Sex \& Health Education among Adolescents \& Young Adults in Pakistan", M.A. Thesis. Centre of Excellence for Women's Studies, University of Karachi.

3 The Columbia Encyclopedia, Sixth Edition Retrieved on 13th Feb 2008 http://www.bartleby.com/65/se/sexual.html

4 Life Skills Based Education LSBE refers to an interactive process of teaching and learning which enables learners to acquire knowledge and to develop attitudes and skills which support the adoption of healthy behaviours. For further details also check http://www.unicef.org/lifeskills/index 12074.html www.wpfpak.org http://www.unfpa.org/adolescents/education.htm 


\section{References:}

Ahmed, Kiran \& Haroon, Uzma (March- April 2003) T. Proliferation of TV Channels in Pakistan, SDPI Research and News Bulletin, Vol. 10, No.2

Chen,M. Sebstad, I \& O'Connell.(1999)Counting the Invisible workforce: The Case of Home Based workers, World Development Vol.27, No. 3, Britain, p-05

Glasier, Anna (et.al) (2007) "Sexual and Reproductive Health: A Matter of Life and Death" in The Lancet Sexual and Reproductive Health Series, October 2006. Retrieved on $14^{\text {th }}$ Feb 2008 www.who.int/reproductive-health/publications/articles/article1.pdf

Human Development Report 2001

Human Development Report 2002

Human Development Report 2003

Human Development Report 2004

Human Development Report 2005

Hussein, Akmal (1994)Poverty Alleviation in Pakistan, Karachi, Vanguard, Lahore. pp 11 $\& 15$

ILO-( 2004), Home Workers: The Silent work force, Centre of Excellence for Women's Studies, p-41

Kiani, Khaleq. Pakistan Rank Low in Social Indicators In Daily Dawn. (Nov 05, 2007)

Kerber, K.L., (2005) Psychology of Ex and Sex Education Series 3, Sex and Society, Global vision publishing house, New Delhi. p- 213

Ministry of Health, Government of Pakistan. (Dec 2001) National Health Policy 2001: The Way Forward, Agenda for Health Sector Reform

NACP, (2000-2001): STI Prevalence Study in Pakistan Retrieved on $14^{\text {th }}$ Feb 2008, http://www.nacp.com.pk/reports.html.

N. Rehan (2003) Profile of Men Suffering from Sexually Transmitted Infections in Pakistan, In Journal of Ayub Medical College, ( JAMC),Abbotabad, Pakistan. AprJun; 15(2):15-19. Retrieved on $25^{\text {th }}$ Feb 2008 http://www.popline.org/docs/1529/278258.html 
Rogers, E.M., (1973) Communication Strategies for Family Planning, The free press, New York, pp 43, 61, 62, 67, 70

WHO, UNICEF UNAIDS, (Dec 2006) Epidemiological Fact Sheets on HIV/ AIDS and Sexually Transmitted Infections Pakistan, Retrieved on $13^{\text {th }} \mathrm{Feb} 2008$ http://www.who.int/globalatlas/predefinedReports/EFS2006/EFS_PDFs/EFS200 $\underline{\text { PK.pdf }}$

Shagufta Nasreen is Lecturer at Centre of Excellence for Women's Studies, University of Karachi, Pakistan. She is enrolled in M.Phil/ Ph.D. Her areas of interest are: Gender and Development, Media and Environment.

Aliyah Ali is Lecturer at Centre of Excellence for Women's Studies, University of Karachi, Pakistan. She is enrolled in M.Phil/ Ph.D. Her areas of interest are: Women and Health, Gender and Development, Women Work, and Technology. 